\title{
Clonality, recombination, and hybridization in the plumbing-inhabiting human pathogen Fusarium keratoplasticum inferred from multilocus sequence typing
}

Dylan PG Short ${ }^{1 *}$, Kerry O'Donnell ${ }^{2}$ and David M Geiser ${ }^{3}$

\begin{abstract}
Background: Recent work has shown that Fusarium species and genotypes most commonly associated with human infections, particularly of the cornea (mycotic keratitis), are the same as those most commonly isolated from plumbing systems. The species most dominant in plumbing biofilms is Fusarium keratoplasticum, a cosmopolitan fungus known almost exclusively from animal infections and biofilms. To better understand its diversity and population dynamics, we developed and utilized a nine-locus sequence-based typing system to make inferences about clonality, recombination, population structure, species boundaries and hybridization.

Results: High levels of genetic diversity and evidence for recombination and clonality were detected among 75 clinical and 156 environmental isolates of Fusarium keratoplasticum. The multilocus sequence typing system (MLST) resolved 111 unique nine-locus sequence types (STs). The single locus bifactorial determinants of mating compatibility (mating types MAT1-1 and MAT1-2), were found in a ratio of 70:30. All but one of the 49 isolates of the most common ST (FSSC 2d-2) came from human infections, mostly of the cornea, and from biofilms associated with contact lenses and plumbing surfaces. Significant levels of phylogenetic incongruence were found among loci. Putative clonal relationships among genotypes were estimated, showing a mixture of large clonal complexes and unrelated singletons. Discordance between the nuclear ribosomal rRNA and other gene genealogies is consistent with introgression of ribosomal RNA alleles of phylogenetic species FSSC 9 into F. keratoplasticum. No significant population subdivision based on clinical versus non-clinical sources was found.
\end{abstract}

Conclusions: Incongruent phylogenetic trees and the presence of both mating types within otherwise identical STs were observed, providing evidence for sexuality in F. keratoplasticum. Cryptic speciation suggested in a published three-locus MLST system was not supported with the addition of new loci, but evidence of introgression of ribosomal RNA genes from another strongly supported phylogenetic species (FSSC 9), also known from plumbing systems and human infections, was detected in two isolates. Overall, F. keratoplasticum is a diverse and geographically unstructured species with a mixed clonal and recombinant life history.

Keywords: Biofilm, Clonality, Fusarium, Hybridization, MLST, Mycotic pathogen, Population dynamics, Recombination

\footnotetext{
* Correspondence: DGeiser@PSU.edu

'Department of Plant Pathology, University of California, Davis, 1636 E Alisal St.,

Salinas, CA 93905, USA

Full list of author information is available at the end of the article
}

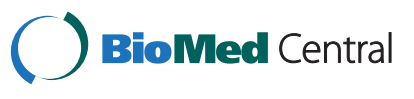

(c) 2014 Short et al.; licensee BioMed Central Ltd. This is an Open Access article distributed under the terms of the Creative Commons Attribution License (http://creativecommons.org/licenses/by/4.0), which permits unrestricted use, distribution, and reproduction in any medium, provided the original work is properly credited. The Creative Commons Public Domain Dedication waiver (http://creativecommons.org/publicdomain/zero/1.0/) applies to the data made available in this article, unless otherwise stated. 


\section{Background}

Fusarium is a large cosmopolitan genus of filamentous fungi best-known for causing a plethora of economically important plant diseases and mycotoxicoses [1]. Fusaria also cause human infections ranging from sinusitis, pneumonia, and localized skin lesions to life-threatening disseminated mycoses in immune-compromised and immune-suppressed individuals [2]. Along with Aspergillus, it is a frequent cause of trauma-associated mycotic keratitis in the tropics [3] and it is a predominant cause of contact-lens associated mycotic keratitis worldwide [4-9]. Fusarium is noted for its resistance to the broadspectrum of antifungal drugs currently available [10]. Multilocus sequence typing (MLST) is a common and powerful tool for elucidating the diversity and population biology of microbial pathogens [11-13]. Several MLST systems have been developed for studying the genetic diversity and population biology of fungal human pathogens including, among others, Aspergillus [14], Blastomyces [15], Candida [16], Coccidioides [17], Cryptococcus [18], Histoplasma [19], and Pneumocystis [20]. Several studies utilizing MLST and genealogical concordance phylogenetic species recognition in Fusarium have revealed strongly supported species boundaries and have elucidated the spectrum of fusaria associated with human pathogenicity $[4,9,12,21-27]$. The application of MLST to mycotic pathogens has identified epidemic clones [28], uncovered signatures of linkage equilibrium associated with sexual recombination [28-30], and revealed cryptic speciation [15,31,32]. Typing systems are also valuable for epidemiological inference and for providing a framework for understanding the distribution of important phenotypes within species such as antimicrobial drug resistance [24].

Knowledge of species boundaries is a prerequisite for studying intraspecific population dynamics [33], and through several molecular systematics studies, the phylogenetic diversity of clinical fusaria has been elucidated [22-24]. Molecular markers useful for phylogenetics tend to utilize coding and intron sequences of various genes and have proved useful for distinguishing not only species, but also common intraspecific sequence types (STs) [26,34-36]. A three-locus MLST system developed for clinically relevant members of the species-rich Fusarium solani species complex (FSSC), which are all nested with Clade 3, utilizes an intron-rich portion of the translation elongation factor 1-alpha gene (TEF), a portion of the nuclear ribosomal RNA gene repeat that includes the internal transcribed spacer (ITS) regions and D1-D2 region of the nuclear large ribosomal RNA subunit gene (rDNA), and the gene encoding RNA polymerase II second largest subunit (RPB2) [24]. This system resolves $\sim 60$ phylogenetic species within the FSSC and distinguishes over 300 genetically distinct STs within Clade 3 of the FSSC [24].
Fusarium continues to be a nosocomial problem and MLST studies have highlighted the prevalence of certain widespread STs in hospital environments [37]. Members of the F. oxysporum species complex (e.g., FOSC ST 33) $[25,37]$ and the FSSC [38], specifically $F$. petroliphilum (e.g., FSSC 1-a) and F. keratoplasticum (e.g., FSSC 2-d) [39], are the fusaria most commonly identified in hospital water systems employing MLST. Clinically important STs within F. keratoplasticum and other fusaria appear to be ubiquitous in indoor plumbing [40,41]. Moreover, multiple STs that are associated with cases of contact lens-associated mycotic keratitis [4] may also be found in this environment $[4,42]$. In fact, based on current analyses [39,41], F. keratoplasticum is the single most common Fusarium species associated with human infections.

Although its monophyly is well-supported $[9,21,24,43]$, F. keratoplasticum (FSSC 2) does not possess any distinctive morphological characters and is highly variable in culture [39], so morphological identification is impossible. Therefore, a three-locus MLST system was developed, which resolved 55 unique STs within $F$. keratoplasticum primarily from clinical sources [24]. In a subsequent expanded analysis, nearly half $(107 / 231)$ of the isolates from clinical and environmental sources belonged to a single ST, FSSC 2-d [39]. In addition to supporting its monophyly, the combined three-locus phylogeny showed a moderately supported partition within F. keratoplasticum, suggesting that further genetic subdivision may exist within this species [24]. Also, evidence suggesting introgressive hybridization between $F$. keratoplasticum and a second FSSC species (FSSC 9) was reported [39].

To better understand the population biology of $F$. keratoplasticum, the three-locus MLST system was expanded to include six novel sequence-based markers, developed using the complete genome sequence of a related species, FSSC 11 (F. solani f. sp pisi) [44]. In addition, a PCR assay for mating-type determination [39] was utilized as a tenth locus to discriminate STs and investigate the potential for sexual reproduction. These markers were used to screen environmental and clinical isolates to infer the intraspecific diversity and relative roles of recombination, clonality, and hybridization in F. keratoplasticum.

\section{Methods}

\section{Isolates of $F$. keratoplasticum}

We analyzed $231 \mathrm{~F}$. keratoplasticum isolates collected from a variety of sources and geographic origins in this study. Sources included human infections $(\mathrm{N}=76)$, plumbing drains $(\mathrm{N}=110)$, as well as veterinary infections, soil and various anthropogenic substrates (Additional file 1: Table S1). The human isolates presented in this paper have come from many sources over decades and were collected in a clinical setting. The isolates were sent from 
clinics for identification. We do not request or maintain personal information about the patients, and only keep data on the body part/disease associated with the isolate, and its general geographic source. Although isolations from six continents are represented, $84 \%$ of the isolates were from North America.

\section{Locus development and primer design}

Six new sequence markers (loci 3968, 3972, 4081, 6512, 5437, and 6549) were developed in this study (Tables 1 and 2), which were utilized in combination with the existing 3-locus system $[21,24,45]$. Based on the optical map of F. solani f. sp. pisi (FSSC 11; also known as 'Nectria' haematococca Mating Population VI (NhMPVI)), the six new markers are predicted to reside on four different chromosomes. Markers were chosen based on the presence of single-nucleotide polymorphisms (SNPs) as well as microsatellites and insertion/deletion polymorphisms (indels) in 20 isolates of F. keratoplasticum and other species in the FSSC (Table 1). The complete genome was downloaded [46] and searched for 500-800 bp regions containing perfect microsatellite repeats using Tandem Repeats Finder [47]. Flanking primers were designed using Primer3 [48].

\section{Nucleic acid manipulation}

Isolates were grown in $5 \mathrm{~mL}$ of potato dextrose broth (PDB) in test tubes for 14 days. Mycelium was then collected, rinsed with sterile distilled water, dried with paper towels, and transferred to $2 \mathrm{~mL}$ tubes for lyophilization. Mycelium was ground to a fine powder using plastic pestles and total genomic DNA was isolated using a DNeasy Plant Minikit protocol (Qiagen, Valencia, CA, USA) and suspended in a $100 \mu \mathrm{l}$ volume of elution buffer. PCR and sequencing was performed using GoTaq PCR Kits (Promega, Madison, WI, USA) in $50 \mu \mathrm{l}$ volumes following the manufacturer's instructions, with reactions subjected to 2 minutes at $94^{\circ} \mathrm{C}, 35$ cycles of 1 minute at $94^{\circ} \mathrm{C}, 1$ minute at the appropriate annealing temperature (Table 2), and 1 minute at $72^{\circ} \mathrm{C}$, followed by 10 minutes at $72^{\circ} \mathrm{C}$. PCR products were sequenced at the Penn State Nucleic Acid Facility, Huck Institute of Life Sciences, University Park, PA. A multiplex PCR for identifying MAT idiomorph was performed as previously described [39]. PCR products were visualized using a $1.5 \% \mathrm{w} / \mathrm{v}$ agarose gel and scored as MAT1-1 or MAT1-2 based on amplicon size ( 200 and $800 \mathrm{bp}$, respectively). Portions of the nuclear ribosomal intergenic spacer region (IGS) were also amplified and sequenced in two putative hybrid isolates as previously described [22] using Invitrogen PlatinumTaq kits (Life Technologies, Carlsbad, CA USA) following the manufacturer's instructions.

\section{Sequence type (ST) diversity}

Isolates were assigned to existing and novel STs as described previously $[4,9,24]$. Briefly, ST assignments were based on their position in terminal nodes in one of 200 maximum parsimony (MP) phylogenetic trees generated by implementation of the parsimony ratchet [49] on concatenated DNA sequence alignments in PAUP*4.0b. Chromatograms were then cross-checked for accuracy to confirm ST membership. Missing or ambiguous DNA positions were assigned Ns in the sequence alignments and treated as missing data. For the nine-locus MLST system, the previously assigned three-locus STs were amended with numerals indicating additional subdivision revealed by the six additional loci. For example, FSSC 2-d, the most common ST in the three-locus system, was subdivided into 18 nine-locus STs designated

Table 1 Characteristics of loci employed

\begin{tabular}{|c|c|c|c|c|c|}
\hline Locus $^{1}$ & Genome position in $\mathrm{MPVI}^{2}$ & P. I. chars. ${ }^{3}$ & SNPs $^{4}$ & No. of indels/Msats: no. of alleles for each ${ }^{5}$ & C. I. ${ }^{6}$ \\
\hline TEF & sca_2_chr3_3_0: 2429595-2430256 & 18 & 23 & $4: 3,3,2,2^{5}$ & 0.75 \\
\hline rDNA & Unknown & 9 & $6^{*}$ & None observed & 0.9 \\
\hline RPB2 & sca_20_chr6_4_0: 1850977-1852794 & 14 & 21 & None observed & 1 \\
\hline 3968 & sca_8_chr1_1_0: 1137337-1138068 & 11 & 17 & $2: 2^{5}, 2$ & 0.95 \\
\hline 3972 & sca_82_chr10_2_0: 791230-792036 & 10 & 17 & None observed & 1 \\
\hline 4081 & sca_8_chr1_1_0: 544046-544635 & 13 & 28 & $5: 2,5,2^{5}, 2^{5}, 2^{5}$ & 0.95 \\
\hline 6512 & sca_26_chr2_2_0: 74409-74990 & 9 & 12 & $2: 2^{5,} 2^{s}$ & 0.93 \\
\hline 5439 & sca_37_chr_6_2_0: 374081-374828 & 6 & 8 & $4: 2^{5}, 2,2^{5}, 2^{5}$ & 1 \\
\hline 5437 & sca_37_chr_6_2_0: 78042-78546 & 25 & 27 & $2: 11,2$ & 0.95 \\
\hline MAT & sca_2_chr3_3_0: N.A. & N.A. & N.A. & N.A. & N.A. \\
\hline
\end{tabular}

1. Name of locus 2. Scaffold, chromosome and inclusive base pairs of targeted sequences in Fusarium solani f. sp. pisi. 3. Number of parsimony informative characters observed within F. keratoplasticum. 4. Number of single nucleotide polymorphisms observed within F. keratoplasticum. 5. Number of total insertion/ deletion and microsatellite polymorphisms observed within F. keratoplasticum (underlined), followed by the number of alleles observed at each, i.e. locus 5437 contains 2 such polymorphisms, one of which has 11 alleles. Superscript s indicates that this polymorphism was found in only one isolate. 6 . Consistency index of individual locus maximum parsimony trees. *Putative hybrids contained 4 more SNPs within their rDNA sequences. 
Table 2 Primer pairs used for PCR amplification and Sanger sequencing

\begin{tabular}{|c|c|c|c|c|c|c|c|}
\hline Locus & Fw primer & Rv primer & $\begin{array}{l}\text { Annealing } \\
\text { temp. }\left({ }^{\circ} \mathrm{C}\right) \\
\end{array}$ & Size $^{1}(b p)$ & Seq. composition (bp) $)^{2}$ & Alleles $^{3}$ & $H^{4}$ \\
\hline TEF & EF1: ATGGGTAAGGARGACAAGAC & EF2: GGARGTACCAGTSATCATGTT & 53 & 667 & 256 intronic; 411 exonic & 22 & 0.89 \\
\hline rDNA & ITS5: GGAAGTAAAAGTCGTAACAAGG & NL4: GGTCCGTGTTTCAAGACGG & 53 & 1029 & 705 coding; 324 ITS & 6 & 0.35 \\
\hline RPB2 5-7 & 5f2: GGGGWGAYCAGAAGAAGGC & 7cr: CCCATRGCTTGYTTRCCCAT & 55 & 863 & Exonic & 11 & 0.51 \\
\hline RPB2 7-11 & 7cf: ATGGGYAARCAAGCYATGGG & 11 ar: GCRTGGATCTTRTCRTCSACC & 55 & 881 & Exonic & - & - \\
\hline 3968 & 3968fw: TGTTGGTTCGAGATGGTTGA & 3968rv: GAGAAGGGCAACTGGGAGA & 53 & 770 & Intergenic & 12 & 0.68 \\
\hline 3972 & 3972fw: TCTGATGCAGACTAGCACTCG & 3972rv: ATCGGACGAAACAGAGCAGG & 53 & 831 & Intergenic & 13 & 0.45 \\
\hline 4081 & 4081fw: TGACRAGGATGAATGAGCGA & 4081rv: TGACCAGCCTCCAAGSG & 56 & 642 & Intergenic & 18 & 0.8 \\
\hline 6512 & 6512fw: GGAGGACCAGGAGGAATAGG & 6512rv: CAAAGCAGATCGACTGAGGA & 53 & 644 & Intergenic & 12 & 0.52 \\
\hline 5439 & 5439fw: AATGGGAATACGAGCGTCAG & 5439rv: AGGGGCTGCTGTTAGTGAGA & 53 & 779 & Intergenic & 10 & 0.48 \\
\hline 5437 & 5437fw: AACAAGACAAGGCAGCAGGT & 5437rv: TCCAGAGGAACGACGAGGC & 56 & 544 & 213 exonic, 331 intergenic & 23 & 0.88 \\
\hline MAT1-1 & MAT1-S-1 F: ATGGCTTTCCGCAGTAAGGA & MAT1-S-1R: CATGATAGGGCAGCAAAGAG & 53 & $\sim 200$ & N. A. & N. A. & N. A. \\
\hline MAT1-2 & MAT2-S-1 F: GGGAATCTGAGAAAGATACGTAC & MAT2-S-1R: CGGTACTGGTAGTCGGGAT & 53 & $\sim 800$ & N. A. & N. A. & N. A. \\
\hline
\end{tabular}

1. Number of characters in the aligned dataset. For different isolates, the exact length of any region may be variable due to indels and microsatellite repeats 2 . ITS $=$ internal transcribed spacers 1 and 2 . Locus 5437 at pubmlst.org. 
FSSC 2-d1 through FSSC 2-d18. SNP and insertiondeletion polymorphisms in the loci were used to distinguish STs. For certain MLST analyses, alleles at each locus were assigned simple numerical identifiers, which we refer to as digitized nine-locus STs; e.g., 16-1-1-4-62-3-4-13 represents a combination of unique alleles observed at the nine loci in ST FSSC 2-c1. 24/2079 (1.2\%) of the nine loci sampled across all isolates produced partial or no sequence data. There were 21 and three isolates missing a significant portion of one or two loci, respectively, and 11 of these cases involved locus 5439. When determining the number of multilocus STs, none were scored as unique by virtue of missing or ambiguous nucleotide data. The number of nine-locus STs was calculated using the digitized nine-locus STs as input into the application DNAcollapser implemented in the website FaBox [50]. Mating type was then used as a tenth locus, with individuals assigned as 1 or 2 based on the detection of the MAT1-1 or MAT1-2 idiomorph and the number of ten-locus STs was calculated in the same way. Nine-locus ST diversity of the total sample was estimated using the formula $[n /(n-1)]\left(1-\Sigma x_{i}^{2}\right)$, where $x_{i}$ is the frequency of the ${ }_{i}$ th ST and $n$ is the number of isolates [51]. Genetic diversity of the loci and mean genetic diversity were calculated from the digitized nine-locus STs using LIAN [52] accessed at (pubmlst.org). To test for patterns of population differentiation, the dataset of 231 isolates was divided into two groups comprising clinical $(\mathrm{n}=76)$ and non-clinical $(\mathrm{n}=155)$ isolates. These groups were clone corrected and an exact test of population differentiation was performed in Arlequin ver 3.11 [53] using the digitized nine-locus STs. Finally, a numerically coded, clone corrected nucleotide sequence dataset with constant characters removed was used for plotting the mean number of genotypes vs. the number of loci in MULTILOCUS, by randomly sampling 1-182 characters 100 times each [54]. Sequence data for the six new loci developed in this study have been deposited in NCBI GenBank (Table 3).

\section{Estimation of clonal relationships}

To generate population snapshots and to estimate clonal relationships among genotypes, the set of 111 unique

Table 3 NCBI GenBank accessions for DNA sequence data for six loci developed for $F$. keratoplasticum

\begin{tabular}{ll}
\hline Locus & GenBank accession numbers \\
\hline 3968 & JN585993-JN586184 \\
3972 & JN586185-JN586372 \\
4081 & JN586373-JN586556 \\
5437 & JN586557-JN586711 \\
5439 & JN586712-JN586899 \\
6512 & JN586900-JN587087 \\
\hline
\end{tabular}

digitized nine-locus STs was used as input into an MLST analysis [55] implemented using the web application eBURST [56], at the single locus variant (SLV) level. The total set of 231 digitized nine-locus STs was also analyzed at the triple locus variant (TLV) level utilizing the goEBURST algorithm [57] implemented in PHYLOVIZ [58]. STs that were not part of any TLV group were added manually as standalone data points. Mating-type data and source information were manually superimposed upon the resulting display of the TLV analysis with high-level edges (connections between STs identical at $7 / 8$ and $6 / 8$ loci) displayed as dashed and dotted lines, respectively. STs of isolates previously reported as producing cyclosporins in vitro $[39,59]$ were indicated on the population snapshots in order to visualize those associated with this phenotype.

\section{Multilocus tests for linkage disequilibrium}

To test for the non-random association of alleles, a clone corrected, digitized nine-locus ST dataset was used to calculate the Index of Association $\left(I_{A}\right)$ [60] together with $\mathrm{rBarD}$, an alternative measure of $I_{\mathrm{A}}$ adjusted for the number of loci, using MULTILOCUS ver. 1.3b [54]. The observed $I_{A}$ and rBarD values were calculated for the nine-locus dataset and compared to 1000 randomized datasets. In addition, a standardized $I_{A}$ was calculated using LIAN [52]. Additionally, to account for potential effects due to physical linkage, $I_{A}$ and $\mathrm{rBarD}$ were recalculated on clone corrected datasets with each of the nine loci removed separately.

\section{Detection of recombination}

A clone corrected, concatenated NEXUS data file with constant characters removed was used to generate a NeighborNet in SPLITSTREE4 [61], and to calculate the dataset's $\delta$ score (a measure of treelikeness, where higher $\delta$ values may reflect higher levels of recombination) [62] and phylogenetic diversity, a measure of diversity based on branch lengths [63]. A clone corrected, concatenated dataset including all nucleotide characters was used to perform the PHI test for recombination [64] implemented in SPLITSTREE4. Incompatibility among all 9 individual gene trees was assessed using COMPAT.PY, a program to detect topological conflict between supported clades in phylogenetic trees [65]. For each of the nine loci, one of 200 MP trees generated using PAUPRAT [49] with branch lengths included was used as input in a test for topological conflict.

\section{Detection of interspecific introgression}

Based on the discovery of two putative hybrids of F. keratoplasticum (FRC S-2406 and FRC S-2509) that possess identical rDNA sequences to those of FSSC 9 [39], sequence data from the nine-locus MLST system were 
generated for three members of FSSC 9 (FRC S-2485, FRC S-2530, FRC S-2540). For comparative purposes, portions of the nine loci were also sequenced for FSSC 5 (FRC S-2519), F. petroliphilum (FSSC 1, FRC S-2550), and F. solani f. sp pisi (FSSC 11) (http://genome.jgi.doe. gov/Necha2/Necha2.home.html). Individual unrooted MP gene trees were generated as described previously to assess whether other loci of the two putative hybrid isolates showed affiliation to FSSC 9. Finally, a portion of the intergenic spacer region of the nuclear ribosomal RNA gene repeat (IGS) was sequenced for the two putative hybrids, three FSSC 9 isolates, and one F. keratoplasticum isolate (NRRL 32710) and analyzed to determine whether this portion of the rRNA repeat was also introgressed.

\section{Results}

\section{F. keratoplasticum shows high levels of ST diversity}

The nine-locus genetic diversity ranged from 0.35 to 0.89 with an average of 0.62 (Table 3 ). One hundred and eleven nine-locus and 122 ten-locus STs (with matingtype as a tenth marker) reflected high levels of diversity in the total sample of 231 isolates. The number of MAT1-1 and MAT1-2 isolates observed was 162 (70\%) and 69 (30\%), respectively. Isolates of seven STs comprised both mating types $(2 \mathrm{~d} 1,2 \mathrm{~d} 2,2 \mathrm{~d} 3,2 \mathrm{f} 2,2 \mathrm{f} 6,2 \mathrm{k} 4$, 2o2). ST diversity was 0.94 among the nine-locus STs, and phylogenetic diversity (PD) of the nine-locus dataset calculated in SPLITSTREE4 was 0.45 (Table 3). Even with 9 loci covering $7650 \mathrm{bp}$, the plot of genotypes vs. number of loci sampled indicates a likelihood of more diversity present within this panel of isolates than was resolved (Figure 1). No strong evidence for cryptic species boundaries within $F$. keratoplasticum was observed, as comparisons between gene trees for each of the nine loci did not reveal any groups with bootstrap values $>60 \%$ in all of the MP trees (data not shown). No population differentiation was detected using exact tests comparing ST diversity of isolates from clinical sources with those from all other sources.

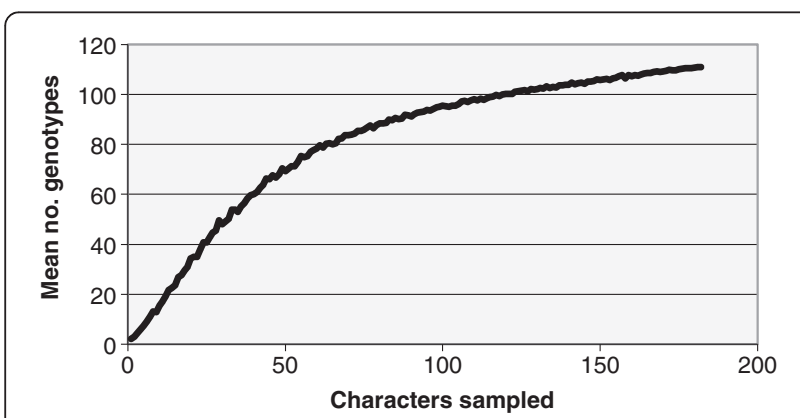

Figure 1 Plot of mean number of genotypes of $F$. keratoplasticum as a function of number of characters (SNPs and indels) sampled.
Inferred relationships among clones and clonal complexes Evolutionary relationships among the $231 \mathrm{~F}$. keratoplasticum isolates inferred using goeBURST resolved nine distinct clonal complexes (i.e. groups of hypothetically clonally related genotypes or clonets). These comprised 50 STs that were defined at the single locus variant (SLV) level (STs identical at 8/9 loci, identified by solid black lines) (Figure 2). Double and triple locus variants (DLV and TLV; STs identical at 7/9 and 6/9 loci, respectively) were also identified by dashed and dotted lines, (Figure 2). Lastly, goeBURST resolved 14 STs comprising 15 isolates that were different at four of more loci (displayed as unconnected STs in Figure 2). Interestingly, included among the singleton STs were the isolate that is the International Organization for Standardization (ISO), ATCC 36031 (ST 2-c1), as well as one of only two confirmed sexually fertile isolates of $F$. keratoplasticum (ST 2-ss1) [39]. Isolates previously known to produce cyclosporins in vitro were found to belong to $F$. keratoplasticum STs 2-d4, 2-d8, 2-d9, 2-d11, 2-ii2, 2-1l1, 2-k1, 2-pp3, 2-ss1, and 2-v1 (Figure 2).

\section{Evidence for non-random association of alleles}

Multiple analyses revealed a statistically significant association of alleles among loci, indicating that isolates may be related through asexual processes of population evolution. The index of association $\left(I_{A}\right)$ and $\mathrm{rBarD}$ calculated from the nine-locus dataset of digitized STs were 0.47 and 0.06 , respectively; both differed significantly from the ranges of these values observed in 1000 artificially recombined datasets $(\mathrm{p}<0.01)$ (Table 4$)$. A standardized $\left(I_{A}\right)$ [52] of 0.059 was calculated using LIAN, and the null hypothesis of linkage equilibrium was rejected using 1000 resamplings in Monte Carlo and parametric tests $\left(\mathrm{p}<0.001\right.$ and $\mathrm{p}<3 \times 10^{-21}$, respectively). To assess the potential contribution of linkage between loci, eight separate tests for linkage disequilibrium were also performed on clone corrected datasets with each locus removed individually. Each of these tests showed significant amounts of linkage disequilibrium (results not shown).

\section{Evidence for recombination}

A net-like and reticulated NeighborNet was observed (Figure 3) and the PHI test for recombination implemented in SPLITSTREE4 supported the presence of recombination $(\mathrm{p}<0.0001)$. The average $\delta$ score for the 111 unique STs using the concatenated dataset showed a significant departure in treelikeness from zero $(\delta=0.28)$ and could be due to the presence of historical recombination events (26). Individual F. keratoplasticum gene trees indicated various levels of intralocus homoplasy, with consistency indices (CI) ranging between 0.75 in TEF to 1.0 in RPB2, 3972, and 5439 (Table 1). 


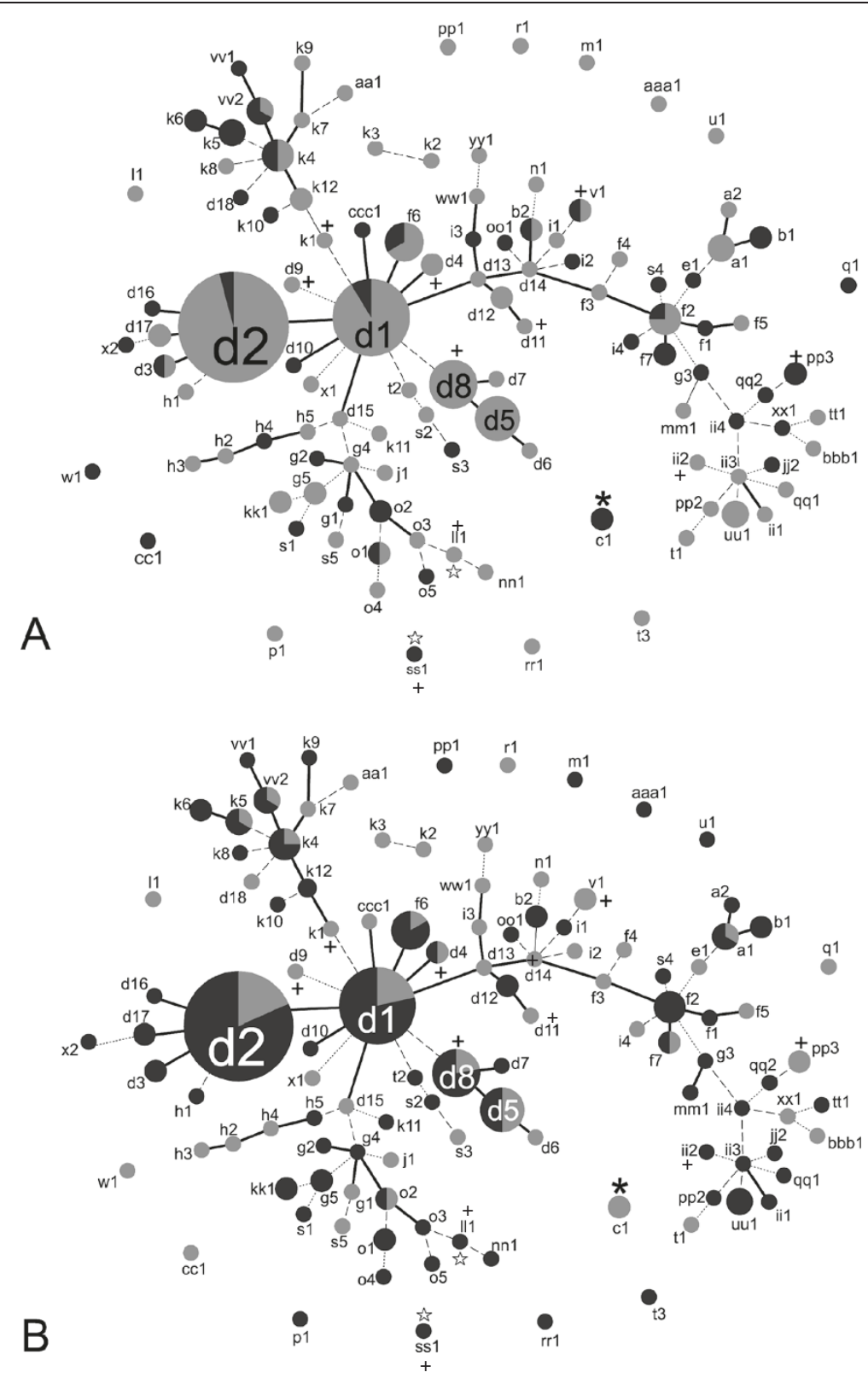

Figure 2 Population snapshots of $F$. keratoplasticum inferred using Phyloviz beta. Each node represents a unique ST (the prefix "2-" has been omitted for clarity); areas of nodes are proportional to the number of isolates. STs with 8/9 loci in common (SLVs) are connected with solid black lines, STs with 7/9 loci in common (DLVs) are connected with dashed lines, STs with 6/9 loci in common (TLVs) are connected with dotted lines. STs different at more than three loci not connected to a group. 9 SLV groups are shown. In $\mathbf{A}$ ) light gray indicates proportion of STs that are MAT1-1; darker gray shading indicates proportion of STs that is MAT1-2. In B) light gray indicates isolates from clinical sources; darker gray indicates isolates from all other sources. Plus signs denote several STs containing isolates known to produce cyclosporin in vitro. Asterisks denote the ST of the ISO standard ATCC 36031 strain. White stars denote STs containing isolates successfully crossed in mating experiments.

COMPAT.PY detected multiple topological conflicts among the trees inferred from the nine loci (results not shown).

\section{Introgression between phylogenetic species}

F. keratoplasticum isolates FRC S-2406 (from Honeymoon Island Park in Florida) and FRC S-2509 (from a shopping center in Georgia) possessed nuclear rDNA regions (ITS, the D1-D2 region of the large subunit, and IGS) that were perfect matches to those found in FSSC 9, suggesting some kind of genetic transfer between $F$. keratoplasticum and this species [39,41]. Phylogenetic analysis of the eight other loci grouped these isolates with F. keratoplasticum (Figure 4). Taken together, these 


\begin{tabular}{|c|c|}
\hline No. isolates & 231 \\
\hline No. nine-locus STs & 111 \\
\hline MAT1-1:MAT1-2 (total) & $162: 69$ \\
\hline MAT1-1:MAT1-2 (without 2-d types) & $64: 60$ \\
\hline Allelic diversity ${ }^{1}$ & 0.94 \\
\hline Average genetic diversity of loci ${ }^{2}$ & 0.62 \\
\hline NeighborNet $\delta$ score $^{3}$ & 0.28 \\
\hline Phylogenetic Diversity ${ }^{4}$ & 0.45 \\
\hline Index of Association ${ }^{5}$ & 0.47 \\
\hline $\mathrm{rBarD}^{6}$ & 0.06 \\
\hline Standardized $I_{A}^{7}$ & 0.05 \\
\hline No. of eBURST SLV groups (clonal complexes) & 9 \\
\hline No. STs connected at SLV level & 50 \\
\hline No. isolates in SLV level STs & 162 \\
\hline No. singletons at SLV level & 69 \\
\hline \multicolumn{2}{|c|}{$\begin{array}{l}\text { 1. ST diversity calculated from Nei (43). 2. Average genetic diversity of the } 9 \\
\text { loci calculated using LIAN }(25) \text {. } 3 \text {. Average } \delta \text { score }(26) \text { of the clone corrected } \\
\text { set of } 111 \text { unique STs calculated using SPLITSTREE. } 4 \text {. Phylogenetic diversity } \\
\text { (19) of the clone corrected set of } 111 \text { unique STs calculated using SPLITSTREE. } \\
\text { 5. Index of Association }(41) \text { calculated using MULTILOCUS } 1.3 b(1) \text { was found } \\
\text { to be significantly different }(p<0.01 \text { ) than } 1000 \text { randomizations, which showed } \\
\text { an expected range of } 2.86-4.09 \text { (mean }=3.46) \text {. } 6 \text {. rBarD calculated using } \\
\text { MULTILOCUS } 1.3 b \text { was found to be significantly different }(p<0.01 \text { ) than } 1000 \\
\text { randomizations, which showed an expected range of } 0.0208-0.0283 \text { (mean = } \\
0.024) \text {. } 7 \text {. Standardized } I_{A} \text { calculated using LIAN }(25) \text {; the null hypothesis of } \\
\text { linkage equilibrium was rejected using } 1000 \text { resamplings in Monte Carlo tests } \\
\text { and a parametric test, with } p<0.001 \text { and } p<3 \times 10^{21} \text { respectively. }\end{array}$} \\
\hline
\end{tabular}

analyses indicated that FRC S-2406 and FRC S-2509 possess ribosomal RNA repeats that are derived from FSSC 9, while the other eight loci have clear origins in $F$. keratoplasticum. Excluding the rDNA of these putative hybrids, the other loci supported reciprocal monophyly between F. keratoplasticum and FSSC 9.

\section{Discussion}

The primary goal of this study was to apply novel sequence based markers to understand the diversity and population biology of $F$. keratoplasticum, the most common clinically relevant Fusarium [21,24]. In addition to their utility in addressing questions related to their basic ecology and epidemiology, MLST in F. keratoplasticum provides a framework for the study of biologically relevant phenotypes. For example, F. keratoplasticum STs vary in the types of secondary metabolites produced, including cyclosporins [39,59] (Figure 2). Sexual fertility also appears to be a variable phenotype within $F$. keratoplasticum. Perithecium formation was previously reported as very rare in crosses of opposite mating types, although a cross between STs 2-ss1 and 2-111 produced recombinant ascospores under laboratory conditions [39]. Finally, biofilm formation in F. keratoplasticum is another variable trait with practical significance. Although NRRL 22641 (=ATCC 36031) was recommended by the International Organization for Standardization guidelines for testing disinfectants, it does not form biofilms in in vitro models [66] and this singleton (ST 2-c1) appears to be quite divergent (Figure 2) and aberrant morphologically [39], casting further doubt on its choice for testing the efficacy of antimicrobials. It is unknown whether this isolate's failure to form biofilms can be attributed to mutation, perhaps post-isolation, or phenotypes segregating in natural populations. In addition to those reported here, further tests of ATCC 36031 in comparison to other clinical isolates has led to the recommendation that multiple clinical isolates be utilized in disinfectant testing [67].

High levels of sequence type diversity in F. keratoplasticum Polymorphisms within the nine loci employed in this study ranged from 6-33 alleles per locus. The six new markers developed in this study were originally targeted because they harbored microsatellite repeats in the $F$. solani f. sp pisi genome. Sequencing these regions in $F$. keratoplasticum revealed high levels of nucleotide polymorphisms in addition to polymorphic repeats, motivating us to utilize them more fully as sequence-based markers and also to avoid issues of convergence that can be problematic in interpreting alleles based on variable numbers of tandem repeats [68]. SNPs were the most common polymorphisms observed within F. keratoplasticum (163 out of $\sim 7650$ characters). Polymorphism per region sequenced was higher than observed in MLST systems of other fungi pathogenic to humans such as Aspergillus fumigatus [14], but lower than the dimorphic mycotic pathogens C. albicans, C. tropicalis and C. glabrata (6). Testing the primers designed in this study against other FSSC species indicated utility of these markers broadly in the complex (Figure 4), as they successfully amplified DNA from F. petroliphilum (FSSC 1), F. falciforme (FSSC $3+4$ ), and FSSC phylogenetic species 5, 9, 18, 22 and 24. Many polymorphisms were found in other FSSC species, especially in the microsatellite repeats, which were extremely variable between species, though the same repeats motifs were often monomorphic within F. keratoplasticum. Although the six new loci developed in this study consisted almost entirely of non-coding sequence residing in intergenic regions, the level of genetic diversity observed at these loci within $F$. keratoplasticum were surprisingly similar to that of the protein-coding genes (Table 2).

Previous MLST studies indicated that environmental and human pathogenic fusaria are diverse, spanning multiple species complexes, species, and STs within species, but certain STs have been found to be dominant. For example, Fusarium oxysporum species complex ST 


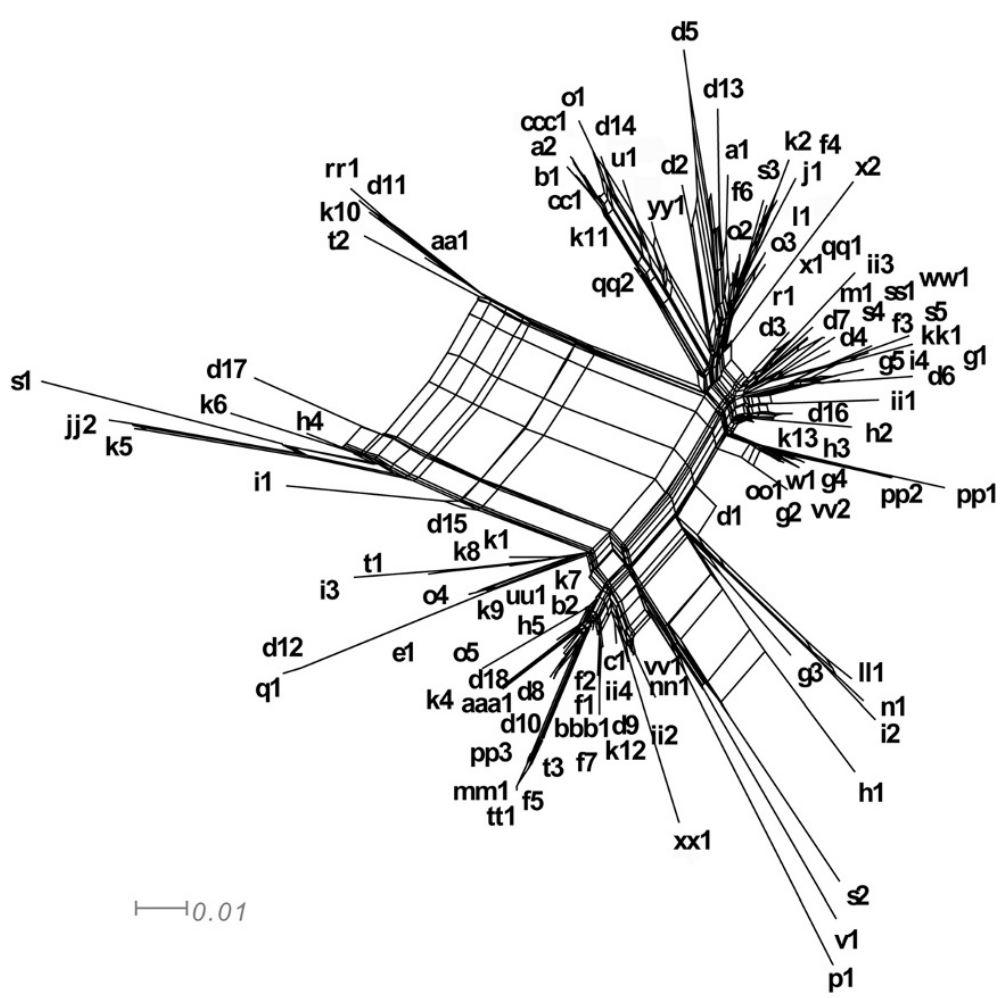

Figure 3 Neighbor net of 111 unique nine-locus haplotypes inferred using SPLITSTREE4. A PHI test for recombination (7) implemented in SPLITSTREE4 suggests a statistically high likelihood of recombination in the full dataset $(p<0.0001)$.

33 was identified as one such widespread clonal lineage based on analysis of TEF and the IGS region. Moreover, analysis of amplified fragment length polymorphisms (AFLPs) revealed seven distinct haplotypes within ST 33 [25]. We observed a similar trend within F. keratoplasticum with the addition of six markers to the 3-locus MLST scheme. The majority of previously defined 3locus STs were further resolved into multiple nine-locus STs (Table 1), some of which appeared to be quite distinct (Figures 2 and 3). Furthermore, the plot of genotypic diversity vs. number of loci sampled indicated that additional diversity in the nine-locus STs remains to be resolved (Figure 1).

\section{F. keratoplasticum has a mixed reproductive mode}

Analyses of F. keratoplasticum isolates revealed evidence of clonality and recombination, mirroring reproductive modes observed in this species. FSSC species reproduce by clonally via asexual propagules (e.g., macroconidia, microconidia, chlamydospores) and several sexually through formation of perithecia and recombinant ascospores These potential modes of reproduction are known in F. keratoplasticum [39]. In contrast to the hypothesis of local sexual neighborhoods, where mating is thought to occur only between isolates of similar genotypes [69], isolates of F. keratoplasticum that produced recombinant ascospores shared only one identical sequence (locus 5439) among the nine loci. The observed frequencies of mating-types in F. keratoplasticum in the total sample deviated significantly from the expected 1:1 ratio (162:69 MAT1-1:MAT1-2; binomial cumulative probability $\mathrm{p}<0.0001)$. This aberration may be due to sampling of the most common widespread clones, because when all 2-d types were removed, a ratio of 64:60 MAT1-1:MAT1-2 (binomial cumulative probability $\mathrm{p}>$ $0.39)$ was observed.

A robust estimate of the contribution of mutation relative to recombination may be calculated as the ratio of STs that form complexes of SLVs, which are assumed to have arisen via mutation, to those that do not. In F. keratoplasticum, $50 \mathrm{STs}$ resolved into 9 clonal complexes of SLVs, comprising 2-22 unique STs each (Figure 2). The remaining number of STs that did not resolve into SLV clonal complexes was 61 , giving an inferred 1:1.24 ratio of mutation:recombination. Without clone correction, however, 162 isolates are connected at the SLV level compared to 69 isolates that are identical at fewer than $8 / 9$ loci, giving an inferred mutation:recombination ratio of 2.3:1. This estimate contrasts with the situation observed in the more clonal Talaromyces marneffei, where the mutation:recombination ratio was approximately 5:1 $[69,70]$. A mixed clonal/recombinant structure has also 


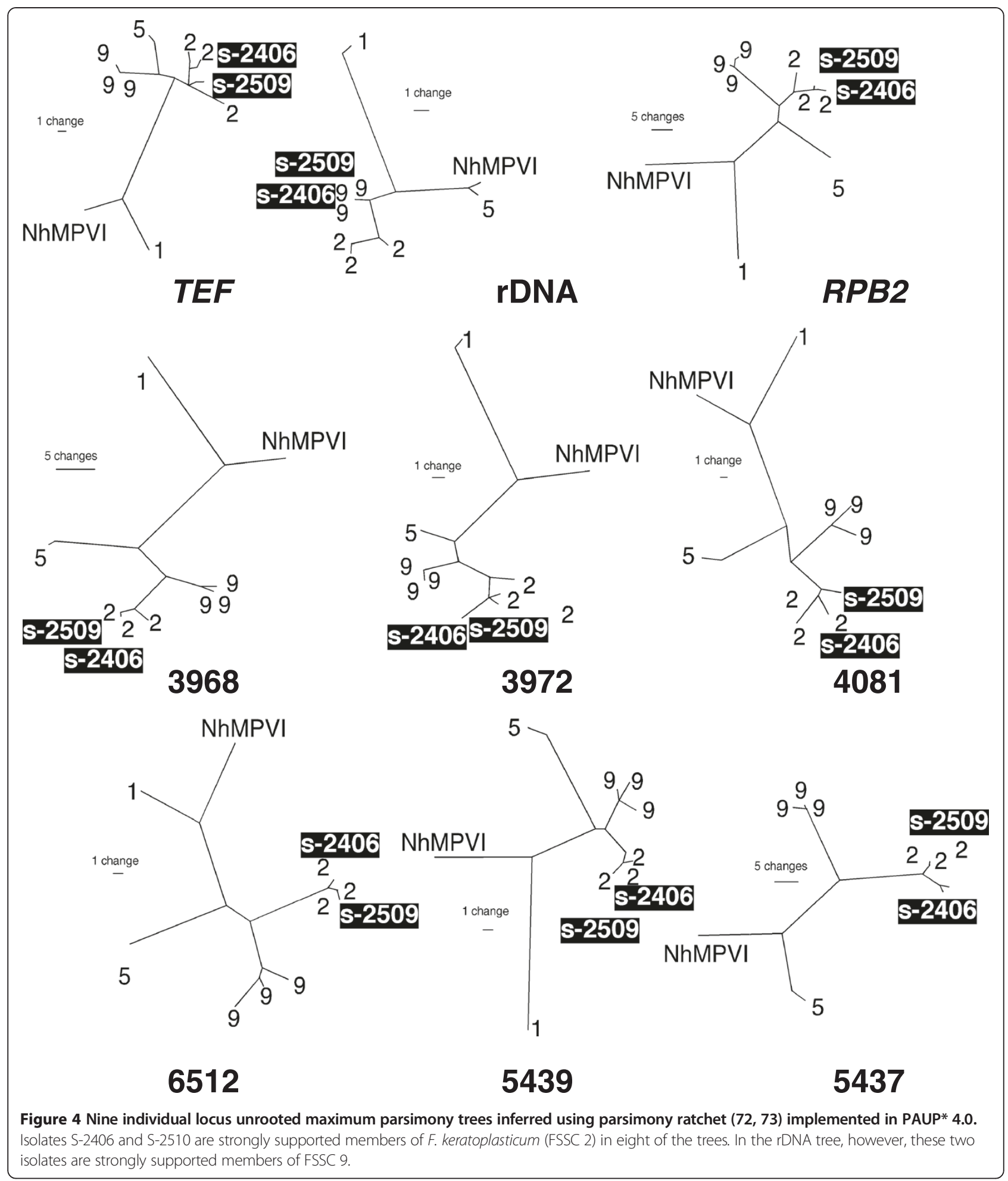

been reported in clinically relevant fungi including Aspergillus fumigatus [32], Cryptococcus gattii [29], Candida albicans [30,71], Candida glabrata [72], and Paracoccidioides brasiliensis [73].

\section{F. keratoplasticum ST 2-d as a transcontinental} epidemic clone

As previously mentioned, F. keratoplasticum 2-d is the three-locus ST most commonly associated with plumbing 
fixture biofilms, including hospital water systems, and human infections. It comprised $46 \%$ of the isolates in our dataset (107 isolates), and despite the incomplete resolution from nine loci, it is retained as a group of related, common and geographically widespread STs. The ninelocus MLST system divided 2-d into 18 unique types, all but one of which are connected through a series of SLVs, DLVs and TLVs (Figures 3 and 2). Based on sequence information, the dominant subtypes 2-d1 and 2-d2 appear to represent a widespread clonal lineage found in the United States, Puerto Rico, Germany, and Qatar (Table 1). Additional evidence of a strong clonal component was provided by the discovery that $94 \%$ of $2-\mathrm{d} 1$ and $2-\mathrm{d} 2$ isolates were MAT1-1 (Figure 2A). The remaining $6 \%$ of 2-d1 and 2-d2 isolates may represent one or multiple separate evolutionary lineages that have not been resolved, even with nine loci. The presence of haplotypes that are both extremely common and widely distributed has been observed in mycotic pathogens such as Cryptococcus gattii [28], in which the same common clone (C. gattii ST7) is present in Australia and the United States. In contrast, ST 2-k, previously shown to be among the six most common biofilm-associated human pathogenic fusaria [41], showed evidence for historical recombination (Figures 3 and 2), as $2-k 2$ and 2-k3 were members of an unconnected TLV group in the eBURST analysis (Figure 2). In support of this, 2-k isolates show a 9:10 MAT1-1:MAT1-2 matingtype ratio, which is similar to the 1:1 ratio expected among randomly mating populations. However, interfertility of the 2-k isolates has not been tested.

\section{Introgression and hybridization}

Introgression has been observed in other medically important fungi including Candida spp. [74], Cryptococcus [75], and Coccidioides [76], and is hypothesized to play an important role in producing diversity. Here, strong evidence of genetic exchange between two isolates of $F$. keratoplasticum and the unnamed species FSSC 9 is presented. FRC isolates S-2406 and S-2509 possessed RPB2 and TEF alleles that clearly placed them in F. keratoplasticum, but their rDNA appeared to have been derived from a FSSC 9 parent (100\% sequence identity to all known FSSC 9 haplotypes). F. keratoplasticum and FSSC 9 are closely related, and both occur in plumbing biofilms, so the simplest explanation for this is introgression via an interspecific hybrid cross. Analyses of these putative hybrids showed that they possessed typical $F$. keratoplasticum alleles at all other loci, suggesting that if the introgression of rDNA was due to a hybridization event, the isolates were likely heavily backcrossed into the F. keratoplasticum background. Hybridization between closely related, phylogenetically defined species has been inferred in Fusarium in multiple instances [77-80]. The introgressed FSSC 9 rDNA included the
ITS regions, the large subunit rRNA, and IGS region, and may encompass the entire rDNA gene repeat. Genome scale analyses are needed to fully assess what portion of the hybrid genomes was derived from a FSSC 9 parent. These analyses may help elucidate whether this introgression was mediated by a sexual or parasexual process. It is also possible that other unorthodox mechanisms may be at play in generating genetic diversity in $F$. keratoplasticum. Species that possess small conditionally dispensible (CD) chromosomes are known to be present within the FSSC [81] as well as in other fusaria [77]. The genome of $F$. solani $\mathrm{f}$. sp pisi includes three CD chromosomes, which disproportionately harbor genes with no clear Fusarium orthologues, leading to the hypothesis that they were gained through unknown horizontal gene transfer (HGT) events [44]. While asexual transfer of CD chromosomes has not been demonstrated in the FSSC, it has been shown experimentally in F. oxysporum [82].

\section{Conclusion}

An extensive body of literature has connected many $\mathrm{Fu}$ sarium infections, particularly ones suspected of being acquired nosocomially, to isolates resident in the patient indoor environment $[21,38,41]$. Similar to what has been observed in other common nosocomially acquired fungal pathogens, including A. fumigatus [83], we found no evidence differentiating clinical isolates from those collected from other sources, including biofilms in plumbing drains (Figure 2B). Although all known isolates of $F$. keratoplasticum are from highly anthropogenically influenced environments, nothing is known about a potential natural reservoir for this species $[21,39,41]$. While some STs show a broad geographic distribution, this MLST system may permit epidemiological inferences connecting patient and indoor environmental STs at a local scale. Diverse genotypes with patterns indicating historical recombination were observed, though there was also strong evidence for clonal expansion of epidemic STs. This mixed reproductive strategy, which is not unusual in fungal pathogens $[28,73,84,85]$, enables the expansion of successful genotypes, at the same time allowing for adaptation to changing environments and antifungal treatment strategies. The detection of natural hybridization and introgression in this sample of isolates may be indicative of another prevalent mechanism permitting adaptation to the anthropogenic environments these fungi inhabit.

\section{Availability of supporting data}

Nucleotide sequence data for $F$. keratoplasticum from the six new sequence markers are available through NCBI GenBank with the following accession numbers: locus 3968: JN585993-JN586184; locus 3972: JN586185JN586372; locus 4081: JN586373-JN586556; locus 5437: 
JN586557-JN586711; locus 5439: JN586712-JN586899; locus 6512: JN586900-JN587087.

\section{Additional file}

Additional file 1: Table S1. 111 nine-locus sequence types and their frequencies based on the diversity of the $231 \mathrm{~F}$. keratoplasticum isolates used in this study.

\section{Competing interests}

The authors declare that they have no competing interests.

\section{Authors' contributions}

DPGS performed all fungal culturing, DNA extraction, marker design and validation, PCR, sequencing, alignment, and analyses and drafted the manuscript. DG and $\mathrm{KO}$ conceived of the study and participated in its design and coordination and helped to draft the manuscript. All authors read and approved the final manuscript.

\section{Acknowledgments}

We thank Jean H. Juba for excellent technical assistance. This work was supported in part by a grant from the National Science Foundation, DEB 0089474 to DMG and Gary J. Samuels, National Institute of Food and Agriculture Project PEN 04527 at the Pennsylvania State Agricultural Experiment Station, and by Bausch and Lomb, Inc. DPGS was supported by NIFA grant 2010-65110-20488, Education in Genomics-Based Microbial Forensics. The mention of firm names or trade products does not imply that they are endorsed or recommended by the US Department of Agriculture over other firms or similar products not mentioned. The USDA is an equal opportunity provider and employer.

\section{Author details}

'Department of Plant Pathology, University of California, Davis, 1636 E Alisal St, Salinas, CA 93905, USA. ${ }^{2}$ Bacterial Foodborne Pathogens and Mycology Research Unit, National Center for Agricultural Utilization Research, US Department of Agriculture, Agricultural Research Service, 1815 North University Street, Peoria, IL 61604, USA. ${ }^{3}$ Department of Plant Pathology \& Environmental Microbiology, The Pennsylvania State University, University Park, PA 16802, USA.

Received: 3 February 2014 Accepted: 16 April 2014

Published: 26 April 2014

\section{References}

1. Leslie JF, Summerell BA: The Fusarium Laboratory Manual. Ames, lowa: Blackwell Publishing; 2006.

2. Nucci $M$, Anaissie E: Fusarium infections in immunocompromised patients. Clin Microbiol Rev 2007, 20(4):695-704.

3. Dóczi I, Gyetvai T, Kredics L, Nagy E: Involvement of Fusarium spp. in fungal keratitis. Clin Microbiol Infect 2004, 10(9):773-776.

4. Chang DC, Grant GB, O'Donnell K, Wannemuehler KA, Noble-Wang J, Rao CY, Jacobson LM, Crowell CS, Sneed RS, Lewis FM, Schaffzin JK, Kainer MA, Genese CA, Alfonso EC, Jones DB, Srinivasan A, Fridkin SK, Park BJ: Multistate outbreak of Fusarium keratitis associated with use of a contact lens solution. J Am Med Assoc 2006, 296(8):953-963.

5. Daniel CS, Rajan MS, Saw VPJ, Claerhout I, Kestelyn P, Dart JKG: Contact lens-related Fusarium keratitis in London and Ghent. Eye 2008, 23(2):484-485.

6. Gaujoux T, Chatel MA, Chaumeil C, Laroche L, Borderie VM: Outbreak of contact lens-related Fusarium keratitis in France. Cornea 2008, 27(9):1018-1021.

7. Khor WB, Aung T, Saw SM, Wong TY, Tambyah PA, Tan AL, Beuerman R, Lim L, Chan WK, Heng WJ, Lim J, Loh RSK, Lee SB, Tan DTH: An outbreak of Fusarium keratitis associated with contact lens wear in Singapore. J Am Med Assoc 2006, 295(24):2867-2873.

8. Ma SE, So K, Chung P, Tsang HT, Chuang S: A multi-country outbreak of fungal keratitis associated with a brand of contact lens solution: the Hong Kong experience. Int J Infect Dis 2009, 13(4):443-448.

9. O'Donnell K, Sarver BA, Brandt M, Chang DC, Noble-Wang J, Park BJ, Sutton DA, Benjamin L, Lindsley M, Padhye A, Geiser DM, Ward TJ: Phylogenetic diversity and microsphere array-based genotyping of human pathogenic fusaria, including isolates from the multistate contact lens-associated US keratitis outbreaks of 2005 and 2006. I Clin Microbiol 2007, 45(7):2235-2248.

10. Speeleveld E, Gordts B, Landuyt HWW, Vroey CD, Raes-Wuytack C: Susceptibility of clinical isolates of Fusarium to antifungal drugs. Mycoses 1996, 39(1-2):37-40.

11. Taylor JW, Fisher MC: Fungal multilocus sequence typing - it's not just for bacteria. Curr Opin Microbiol 2003, 6(4):351-356.

12. Balajee SA, Borman AM, Brandt ME, Cano J, Cuenca-Estrella M, Dannaoui E, Guarro J, Haase G, Kibbler CC, Meyer W, O'Donnell K, Petti CA, RodriguezTudela JL, Sutton D, Velegraki A, Wickes BL: Sequence-based identification of Aspergillus, Fusarium, and Mucorales species in the clinical mycology laboratory: where are we and where should we go from here? J Clin Microbiol 2009, 47(4):877-884

13. Campbell LT, Carter DA: Looking for sex in the fungal pathogens Cryptococcus neoformans and Cryptococcus gattii. FEMS Yeast Res 2006, 6(4):588-598.

14. Bain JM, Tavanti A, Davidson AD, Jacobsen MD, Shaw D, Gow NAR, Odds FC: Multilocus sequence typing of the pathogenic fungus Aspergillus fumigatus. J Clin Microbiol 2007, 45(5):1469-1477.

15. Brown EM, MCTaggart LR, Zhang SX, Low DE, Stevens DA, Richardson SE: Phylogenetic analysis reveals a cryptic species Blastomyces gilchristii, sp. nov. within the human pathogenic fungus Blastomyces dermatitidis. PLoS One 2013, 8(3):e59237.

16. Lin CY, Chen YC, Lo HJ, Chen KW, Li SY: Assessment of Candida glabrata strain relatedness by pulsed-field gel electrophoresis and multilocus sequence typing. J Clin Microbiol 2007, 45(8):2452-2459.

17. Burt A, Dechairo BM, Koenig GL, Carter DA, White TJ, Taylor JW: Molecular markers reveal differentiation among isolates of Coccidioides immitis from California, Arizona and Texas. Mol Ecol 1997, 6(8):781-786.

18. Meyer W, Aanensen DM, Boekhout T, Cogliati M, Diaz MR, Esposto MC Fisher M, Gilgado F, Hagen F, Kaocharoen S: Consensus multi-locus sequence typing scheme for Cryptococcus neoformans and Cryptococcus gattii. Med Mycol 2009, 47(6):561-570.

19. Balajee SA, Hurst SF, Chang LS, Miles M, Beeler E, Hale C, Kasuga T, Benedict $\mathrm{K}$, Chiller T, Lindsley MD: Multilocus sequence typing of Histoplasma capsulatum in formalin-fixed paraffin-embedded tissues from cats living in non-endemic regions reveals a new phylogenetic clade. Med Mycol 2013, 51(4):345-351.

20. Maitte C, Leterrier M, Le Pape P, Miegeville M, Morio F: Multilocus sequence typing of Pneumocystis jirovecii from clinical samples: how many and which loci? J Clin Microbiol 2013, 59(9):2843-2849.

21. Zhang N, O'Donnell K, Sutton DA, Nalim FA, Summerbell RC, Padhye AA, Geiser DM: Members of the Fusarium solani species complex that cause infections in both humans and plants are common in the environment. J Clin Microbiol 2006, 44(6):2186-2190.

22. O'Donnell K, Gueidan C, Sink S, Johnston PR, Crous PW, Glenn A, Riley R, Zitomer NC, Colyer P, Waalwijk C, van der Lee T, Moretti A, Kang S, Kim HS, Geiser DM, Juba JH, Baayen RP, Cromey MG, Bithell S, Sutton DA, Skovgaard K, Ploetz R, Kistler HC, Elliott M, Davis M, Sarver BAJ: A two-locus DNA sequence database for typing plant and human pathogens within the Fusarium oxysporum species complex. Fungal Genet Biol 2009, 46(12):936-948.

23. O'Donnell K, Sutton DA, Rinaldi MG, Gueidan C, Crous PW, Geiser DM: Novel multilocus sequence typing scheme reveals high genetic diversity of human pathogenic members of the Fusarium incarnatum-F. equiseti and $F$. chlamydosporum species complexes within the United States. J Clin Microbiol 2009, 47(12):3851-3861.

24. O'Donnell K, Sutton DA, Fothergill A, McCarthy D, Rinaldi MG, Brandt ME, Zhang N, Geiser DM: Molecular phylogenetic diversity, multilocus haplotype nomenclature, and in vitro antifungal resistance within the Fusarium solani species complex. J Clin Microbiol 2008, 46(8):2477-2490.

25. O'Donnell K, Sutton DA, Rinaldi MG, Magnon KC, Cox PA, Revankar SG, Sanche S, Geiser DM, Juba JH, van Burik JH, Anaissie EJ, Francesconi A, Walsh TJ, Robinson JS: Genetic diversity of human pathogenic members of the Fusarium oxysporum complex inferred from multilocus DNA sequence data and amplified fragment length polymorphism analyses: evidence for the recent dispersion of a geographically widespread clonal lineage and nosocomial origin. J Clin Microbiol 2004, 42(11):5109-5120.

26. O'Donnell K, Sutton DA, Rinaldi MG, Sarver BA, Balajee SA, Schroers HJ, Summerbell RC, Robert VA, Crous PW, Zhang N, Aoki T, Jung K, Park J, Lee 
YH, Kang S, Park B, Geiser DM: Internet-accessible DNA sequence database for identifying fusaria from human and animal infections. J Clin Microbiol 2010, 48(10):3708-3718.

27. Wang H, Xiao M, Kong F, Chen S, Dou HT, Sorrell T, Li RY, Xu YC: Accurate and practical identification of 20 Fusarium species by seven-locus sequence analysis and reverse line blot hybridization, and an in vitro antifungal susceptibility study. J Clin Microbiol 2011, 49(5):1890-1898.

28. Carriconde F, Gilgado F, Arthur I, Ellis D, Malik R, van de Wiele N, Robert V, Currie BJ, Meyer W: Clonality and a-a recombination in the Australian Cryptococcus gattii VGII population-an emerging outbreak in Australia. PLoS One 2011, 6(2):e16936.

29. Campbell LT, Currie BJ, Krockenberger M, Malik R, Meyer W, Heitman J, Carter D: Clonality and recombination in genetically differentiated subgroups of Cryptococcus gattii. Eukaryot Cell 2005, 4(8):1403-1409.

30. Tavanti A, Gow NAR, Maiden MCJ, Odds FC, Shaw DJ: Genetic evidence for recombination in Candida albicans based on haplotype analysis. Fungal Genet Biol 2004, 41(5):553-562

31. Koufopanou V, Burt A, Szaro T, Taylor JW: Gene genealogies, cryptic species, and molecular evolution in the human pathogen Coccidioides immitis and relatives (Ascomycota, Onygenales). Mol Biol Evol 2001, 18(7):1246-1258

32. Pringle A, Baker DM, Platt JL, Wares JP, Latge JP, Taylor JW: Cryptic speciation in the cosmopolitan and clonal human pathogenic fungus Aspergillus fumigatus. Evolution 2005, 59(9):1886-1899.

33. Taylor JW, Geiser DM, Burt A, Koufopanou V: The evolutionary biology and population genetics underlying fungal strain typing. Clin Microbiol Rev 1999, 12(1):126-146.

34. Debourgogne A, Gueidan C, de Hoog S, Lozniewski A, Machouart M: Comparison of two DNA sequence-based typing schemes for the Fusarium solani species complex and proposal of a new consensus method. J Microbiol Methods 2012, 9(1):65-72.

35. Debourgogne A, Gueidan C, Hennequin C, Contet-Audonneau N, de Hoog S, Machouart M: Development of a new MLST scheme for differentiation of Fusarium solani Species Complex (FSSC) isolates. J Microbiol Methods 2010, 82(3):319-323.

36. Park B, Park J, Cheong KC, Choi J, Jung K, Kim D, Lee YH, Ward TJ, O'Donnell K, Geiser DM: Cyber infrastructure for Fusarium: three integrated platforms supporting strain identification, phylogenetics, comparative genomics and knowledge sharing. Nucleic Acids Res 2011, 39(suppl 1):D640-D646.

37. Scheel CM, Hurst SF, Barreiros G, Akiti T, Nucci M, Balajee SA: Molecular analyses of Fusarium isolates recovered from a cluster of invasive mold infections in a Brazilian hospital. BMC Infect Dis 2013, 13(1):49.

38. Anaissie EJ, Kuchar RT, Rex JH, Francesconi A, Kasai M, Müller FC, Mario L, Summerbell RC, Dignani MC, Chanock SJ, Walsh TJ: Fusariosis associated with pathogenic Fusarium species colonization of a hospital water system: a new paradigm for the epidemiology of opportunistic mold infections. Clin Infect Dis 2001, 33(11):1871-1878.

39. Short DPG, O'Donnell K, Thrane U, Nielsen KF, Zhang N, Juba JH, Geiser DM: Phylogenetic relationships among members of the Fusarium solani species complex in human infections and the descriptions of $F$. keratoplasticum sp. nov. and F. petroliphilum stat. nov. Fungal Genet Biol 2013, 53:59-70.

40. Mehl HL, Epstein L: Sewage and community shower drains are environmental reservoirs of Fusarium solani species complex group 1 a human and plant pathogen. Environ Microbio/ 2008, 10(1):219-227.

41. Short DPG, O'Donnell K, Zhang N, Juba JH, Geiser DM: Widespread occurence of human pathogenic types of the fungus Fusarium detected in plumbing drains. J Clin Microbiol 2011, 49:4262-4272.

42. Alfonso EC, Rosa RH, Miller D: Fungal keratitis. Cornea 1997, 2:1253-1265.

43. O'Donnell K, Ward TJ, Aberra D, Kistler HC, Aoki T, Orwig N, Kimura M, Bjørnstad A, Klemsdal SS: Multilocus genotyping and molecular phylogenetics resolve a novel head blight pathogen within the Fusarium graminearum species complex from Ethiopia. Fungal Genet Biol 2008, 45(11):1514-1522.

44. Coleman JJ, Rounsley SD, Rodriguez-Carres M, Kuo A, Wasmann CC, Grimwood J, Schmutz J, Taga M, White GJ, Zhou S, Schwartz DC, Freitag M, Ma LJ, Danchin EGJ, Henrissat B, Coutinho PM, Nelson DR, Straney D, Napoli CA, Barker BM, Gribskov M, Rep M, Kroken S, Molnár I, Rensing C, Kennell JC, Zamora J, Farman ML, Selker EU, Salamov A, et al: The genome of Nectria haematococca: contribution of supernumerary chromosomes to gene expansion. PLoS Genet 2009, 5(8):e1000618.
45. O'Donnell K, Cigelnik E, Nirenberg HI: Molecular systematics and phylogeography of the Gibberella fujikuroi species complex. Mycologia 1998, 90(3):465-493.

46. Nectria haematococca v2.0. http://genome.jgi.doe.gov/Necha2/Necha2. home.html.

47. Tandem Repeats Finder. http://tandem.bu.edu/trf/trf.html.

48. Primer3web version 4.0.0. http://frodo.wi.mit.edu/primer3.

49. Sikes DS, Lewis PO: Beta software, version 1. PAUPRat: PAUP* implementation of the parsimony ratchet. Distributed by the authors. Department of Ecology and Evolutionary Biology. Storrs, CT, USA: University of Connecticut; 2001.

50. Villesen P: FaBox: an online toolbox for fasta sequences. Mol Ecol Notes 2007, 7(6):965-968.

51. Nei M, Tajima F: DNA polymorphism detectable by restriction endonucleases. Genetics 1981, 97(1):145-163.

52. Haubold B, Hudson RR: LIAN 3.0: detecting linkage disequilibrium in multilocus data. Bioinformatics 2000, 16(9):847-849.

53. Excoffier L, Laval G, Schneider S: Arlequin (version 3.0): an integrated software package for population genetics data analysis. Evol Bioinform Online 2005, 1:47.

54. Agapow PM, Burt A: Indices of multilocus linkage disequilibrium. Mol Ecol Notes 2001, 1(1-2):101-102.

55. Spratt BG, Hanage WP, Li B, Aanensen DM, Feil EJ: Displaying the relatedness among isolates of bacterial species - the eBURST approach. FEMS Microbiol Lett 2004, 241(2):129-134.

56. eBURSTv3. http://eburst.mlst.net.

57. Francisco AP, Bugalho M, Ramirez M, Carriço JA: Global optimal eBURST analysis of multilocus typing data using a graphic matroid approach. BMC Bioinforma 2009, 10(1):152.

58. Francisco AP, Vaz C, Monteiro PT, Melo-Cristino J, Ramirez M, Carriço J: PHYLOViZ: phylogenetic inference and data visualization for sequence based typing methods. BMC Bioinforma 2012, 13(1):87.

59. Sugiura Y, Barr JR, Barr DB, Brock JW, Elie CM, Ueno Y, Patterson DG Jr, Potter ME, Reiss E: Physiological characteristics and mycotoxins of human clinical isolates of Fusarium species. Mycol Res 1999, 103(11):1462-1468.

60. Smith JM, Smith NH, O'Rourke M, Spratt BG: How clonal are bacteria? Proc Natl Acad Sci U S A 1993, 90(10):4384-4388.

61. Huson DH: SplitsTree: analyzing and visualizing evolutionary data. Bioinformatics 1998, 14(1):68-73.

62. Holland BR, Huber KT, Dress A, Moulton V: $\delta$ plots: a tool for analyzing phylogenetic distance data. Mol Biol Evol 2002, 19(12):2051-2059.

63. Faith DP: Conservation evaluation and phylogenetic diversity. Biol Conserv 1992, 61(1):1-10.

64. Bruen TC, Philippe $H$, Bryant D: A simple and robust statistical test for detecting the presence of recombination. Genetics 2006, 172(4):2665-2681.

65. Kauff F, Lutzoni F: Phylogeny of the Gyalectales and Ostropales (Ascomycota, Fungi): among and within order relationships based on nuclear ribosomal RNA small and large subunits. Mol Phylogenet Evol 2002, 25(1):138-156.

66. Imamura Y, Chandra J, Mukherjee PK, Lattif AA, Szczotka-Flynn LB, Pearlman E, Lass JH, O'Donnell K, Ghannoum MA: Fusarium and Candida albicans biofilms on soft contact lenses: model development, influence of lens type, and susceptibility to lens care solutions. Antimicrob Agents Chemother 2008, 52(1):171-182.

67. Hume EBH, Flanagan J, Masoudi S, Zhu H, Cole N, Willcox MD: Soft contact lens disinfection solution efficacy: clinical Fusarium isolates vs. ATCC 36031. Optom Vis Sci 2009, 86(5):415-419.

68.x Avise JC: Molecular Markers, Natural History, and Evolution Second Edition. Sunderland MA: Sinauer Associates; 2004.

69. Henk DA, Shahar-Golan R, Devi KR, Boyce KJ, Zhan N, Fedorova ND, Nierman WC, Hsueh PR, Yuen KY, Sieu TPM, Van Kinh N, Wertheim H, Baker SG, Day JN, Vanittanakom N, Bignell EM, Andrianopoulos A, Fisher MC: Clonality despite sex: the evolution of host-associated sexual neighborhoods in the pathogenic fungus Penicillium marneffei. PLoS Pathog 2012, 8(10):e1002851.

70. Fisher M: The evolutionary implications of an asexual lifestyle manifested by Penicillium marneffei. In Sex in Fungi: Molecular Determination and Evolutionary Implications. Edited by Heitman J, Kronstad JW, Taylor JW, Casselton LA. Washington, DC: ASM Press; 2005.

71. Gräser Y, Volovsek M, Arrington J, Schönian G, Presber W, Mitchell TG, Vilgalys R: Molecular markers reveal that population structure of the human pathogen Candida albicans exhibits both clonality and recombination. Proc Natl Acad Sci U S A 1996, 93(22):12473-12477. 
72. Dodgson AR, Pujol C, Pfaller MA, Denning DW, Soll DR: Evidence for recombination in Candida glabrata. Fungal Genet Biol 2005, 42(3):233-243.

73. Matute DR, McEwen JG, Puccia R, Montes BA, San-Blas G, Bagagli E, Rauscher JT, Restrepo A, Morais F, Niño-Vega G, Taylor JW: Cryptic speciation and recombination in the fungus Paracoccidioides brasiliensis as revealed by gene genealogies. Mol Biol Evol 2006, 23(1):65-73.

74. Pujol C, Daniels KJ, Lockhart SR, Srikantha T, Radke JB, Geiger J, Soll DR: The closely related species Candida albicans and Candida dubliniensis can mate. Eukaryot Cell 2004, 3(4):1015-1027.

75. Kavanaugh LA, Fraser JA, Dietrich FS: Recent evolution of the human pathogen Cryptococcus neoformans by intervarietal transfer of a 14-gene fragment. Mol Biol Evol 2006, 23(10):1879-1890.

76. Neafsey DE, Barker BM, Sharpton TJ, Stajich JE, Park DJ, Whiston E, Hung CY, McMahan C, White J, Sykes S, Heiman D, Young S, Zeng Q, Abouelleil A, Aftuck L, Bessette D, Brown A, FitzGerald M, Lui A, Macdonald JP, Priest M, Orbach MJ, Galgiani JN, Kirkland TN, Cole GT, Birren BW, Henn MR, Taylor JW, Rounsley SD: Population genomic sequencing of Coccidioides fungi reveals recent hybridization and transposon control. Genome Res 2010, 20(7):938-946.

77. Jurgenson JE, Bowden RL, Zeller KA, Leslie JF, Alexander NJ, Plattner RD: A genetic map of Gibberella zeae (Fusarium graminearum). Genetics 2002, 160(4):1451-1460.

78. Kasson MT, O'Donnell K, Rooney AP, Sink S, Ploetz RC, Ploetz JN, Konkol JL, Carrillo D, Freeman S, Mendel Z, Smith JA, Black AW, Hulcr J, Bateman C, Stefkova K, Campbell PR, Geering ADW, Dann EK, Eskalen A, Mohotti K, Short DPG, Aoki T, Fenstermacher KA, Davis DD, Geiser DM: An inordinate fondness for Fusarium: phylogenetic diversity of fusaria cultivated by ambrosia beetles in the genus Euwallacea on avocado and other plant hosts. Fungal Genet Biol 2013, 56:147-157.

79. O'Donnell K, Kistler HC, Tacke BK, Casper HH: Gene genealogies reveal global phylogeographic structure and reproductive isolation among lineages of Fusarium graminearum, the fungus causing wheat scab. Proc Natl Acad Sci U S A 2000, 97(14):7905-7910.

80. Zeller KA, Bowden RL, Leslie JF: Population differentiation and recombination in wheat scab populations of Gibberella zeae from the United States. Mol Ecol 2004, 13(3):563-571.

81. Miao VP, Covert SF, Van Etten HD: A fungal gene for antibiotic resistance on a dispensable (" B") chromosome. Science 1991, 254(5039):1773-1776.

82. Ma LJ, van der Does HC, Borkovich KA, Coleman JJ, Daboussi MJ, Di Pietro A, Dufresne M, Freitag M, Grabherr M, Henrissat B, Houterman PM, Kang S, Shim WB, Woloshuk C, Xie X, Xu JR, Antoniw J, Baker SE, Bluhm BH, Breakspear A, Brown DW, Butchko RAE, Chapman S, Coulson R, Coutinho PM, Danchin EGJ, Diener A, Gale LR, Gardiner DM, Goff S, et al: Comparative genomics reveals mobile pathogenicity chromosomes in Fusarium. Nature 2010, 464(7287):367-373.

83. Paoletti M, Rydholm C, Schwier EU, Anderson MJ, Szakacs G, Lutzoni F, Debeaupuis JP, Latgé JP, Denning DW, Dyer PS: Evidence for sexuality in the opportunistic fungal pathogen Aspergillus fumigatus. Curr Biol 2005, 15(13):1242-1248.

84. Odds FC, Bougnoux ME, Shaw DJ, Bain JM, Davidson AD, Diogo D, Jacobsen MD, Lecomte M, Li SY, Tavanti A, Maiden MCJ, Gow NAR, d'Enfert C: Molecular phylogenetics of Candida albicans. Eukaryot Cell 2007, 6(6):1041-1052.

85. Carter DA, Burt A, Taylor JW, Koenig GL, White TJ: Clinical isolates of Histoplasma capsulatum from Indianapolis, Indiana, have a recombining population structure. J Clin Microbiol 1996, 34(10):2577-2584.

doi:10.1186/1471-2148-14-91

Cite this article as: Short et al: Clonality, recombination, and hybridization in the plumbing-inhabiting human pathogen Fusarium keratoplasticum inferred from multilocus sequence typing. BMC

Evolutionary Biology 2014 14:91

\section{Submit your next manuscript to BioMed Central and take full advantage of:}

- Convenient online submission

- Thorough peer review

- No space constraints or color figure charges

- Immediate publication on acceptance

- Inclusion in PubMed, CAS, Scopus and Google Scholar

- Research which is freely available for redistribution 